\title{
Detecting the Origins of Moisture over Southeast China: Seasonal Variation and Heavy Rainfall
}

\author{
Xiuzhen $\mathrm{LI}^{1}$, Wen $\mathrm{ZHOU}^{* 2}$, and Yongqin David CHEN ${ }^{3}$ \\ ${ }^{1}$ Department of Geography and Resource Management, The Chinese University of Hong Kong, Hong Kong \\ ${ }^{2}$ Guy Carpenter Asia-Pacific Climate Impact Centre, School of Energy and Environment, City University of Hong Kong, Hong Kong \\ ${ }^{3}$ Department of Geography and Resource Management, and Institute of Environment, Energy and Sustainability, \\ The Chinese University of Hong Kong, Hong Kong
}

(Received 24 March 2015; revised 25 August 2015; accepted 2 September 2015)

\begin{abstract}
To examine the ability of the Hybrid Single-Particle Lagrangian Integrated Trajectory (HYSPLIT) model to detect the origins and paths of moisture supplied to Southeast China, trajectories of air particles released over Southeast China were traced backward during 1 April 2012 to 31 March 2013 and three typical regional persistent heavy rainfall events. The HYSPLIT model provides more insightful information than water vapor flux. Analysis of the specific humidity along the trajectories revealed the origins of moisture and their contributions to the moisture supply in Southeast China. In the boreal summer half year, four key moisture transport paths from the eastern Indian Ocean, central Indian Ocean, South China Sea (SCS), and western North Pacific (WNP) contribute 10\%, 20\%, 31\%, and 16\% of the moisture to Southeast China, respectively. In the winter half year, the contributions of the paths from the WNP and North China double. Examination of heavy rainfall events showed that under tropical storm conditions, all moisture transport routines are rotated cyclonically before reaching Southeast China. The invasion of cold air can trigger heavy rainfall in both the summer and winter half years but plays different roles: it does not contribute to the moisture supply but plays a key role in converging and uplifting the moisture in the summer half year, while it supplies a great amount of moisture in the winter half year as it absorbs abundant moisture in crossing the WNP.
\end{abstract}

Key words: moisture origin, Southeast China, HYSPLIT, seasonal variation, heavy rainfall

Citation: Li, X. Z., W. Zhou, and Y. Q. Chen, 2016: Detecting the origins of moisture over Southeast China: Seasonal variation and heavy Rainfall. Adv. Atmos. Sci., 33(3), 319-329, doi: 10.1007/s00376-015-4197-5.

\section{Introduction}

Where does today's rain come from? This is a simple and important question, but no clear answer has yet been found. Generally, precipitation arises from two sources: local evaporation and externally advected moisture. Local evaporation is subject to the availability of surface water, with the magnitude of its variation much less than that of heavy rainfall. During a heavy rainfall event, rainfall-producing weather systems extend to about 3-5 times the radius of the sink region to absorb moisture (Trenberth et al., 2003). The water vapor transported by atmospheric circulation is one of the most important processes in the hydrological cycle.

Southeast China experiences a typical monsoon climate and shows great seasonal variability in its moisture circulation. In the summer half year, the East Asian summer monsoon prevails: abundant moisture is imported by the southwest flow from the Indian Ocean, the southeast flow from the

\footnotetext{
* Corresponding author: Wen ZHOU

Email: wenzhou@cityu.edu.hk
}

western North Pacific (WNP), and the cross-equatorial flow from the southern hemisphere (Li et al., 2012). In the winter half year, the northeast winter monsoon prevails: Southeast China tends to lack moisture, except for limited moisture transported by the midlatitude westerly and the southwesterly ahead of the India-Burma trough (Qin et al., 1991; Li et al., 2010). At the synoptic scale, a large supply of moisture makes Southeast China vulnerable to heavy rainstorms (Tao and Ding, 1981; Ding, 1994; Bao and Huang, 2006). Generally, three typical types of heavy rainstorms can be categorized based on their triggering systems. One is caused by a quasi-stationary front in the first rainy season (April to June) with a subtropical high anchoring to the south of Southeast China. The second is attributed to the persistence of a depression - typically, a landed tropical cyclone-in the second rainy season (July to September; Bao, 2007). The last type is triggered by a sudden outbreak of strong cold air activity conflicting with preexisting warm and humid air outside the rainy seasons.

Previous studies on moisture sources have been based mainly on water vapor flux, which is qualitative. A more 
objective and quantitative investigation is therefore desirable to study the importance of each moisture source. The Hybrid Single-Particle Lagrangian Integrated Trajectory (HYSPLIT) model (Draxler and Rolph, 2003), which traces air particles released at any height and location backward and calculates specific meteorological variables along the trajectories by solving the Lagrangian equation, is now widely applied in the study of moisture origins of extreme precipitation (e.g., Draxler and Rolph, 2003; Stohl et al., 2003). An analysis of the specific humidity along a backward trajectory allows an exploration of the role of air particles in transporting moisture and the possible moisture origin where evaporation occurs. By applying HYSPLIT, Gustafsson et al. (2010) found that moisture crosses continental Europe and the Baltic Sea before arriving in southern Sweden during extreme summer precipitation. Fuhrmann and Konrad II (2013) found that snowfall and ice storms in central North Carolina entrain different moisture sources, with the former over the Caribbean Sea and the latter over the Gulf of Mexico and the Carolina coast. Brimelow and Reuter (2005) found that the low-level moisture feeding three extreme rainfall events over the southern Mackenzie River basin could be traced back to the Gulf of Mexico. Over China, Jiang et al. (2011) pointed out that moisture sources vary during different phases of heavy rainfall over the Huaihe valley.

In this study, the HYSPLIT model was applied to detect the possible pathways of the moisture responsible for precipitation over Southeast China. The data are described briefly in section 2. The seasonal variations in moisture origins and paths are examined in section 3, based on the results from a HYSPLIT run during 1 April 2012 to 31 March 2013. The moisture sources of three typical heavy rainfall events are studied in section 4 to investigate the similarities within each category and the dissimilarities among different categories. A summary and further discussion are provided in section 5.

\section{Data and methodology}

Gauge-based daily precipitation data during 1979-2012 from 756 stations over China, subjected to quality control procedures by the China Meteorological Administration (Bao, 2007), were used to count the regional durative heavy rainfall events over Southeast China. They were defined preliminarily, referring to the study of Bao (2007), as processes in a region in which 3-day precipitation exceeded $100 \mathrm{~mm}$ and daily precipitation exceeded $25 \mathrm{~mm}$. The threshold of the region size was over 10 stations within a flexible rectangle containing 50 grids with a $1^{\circ} \times 1^{\circ}$ horizontal resolution over Southeast China $\left(21^{\circ}-28^{\circ} \mathrm{N}, 105^{\circ}-120^{\circ} \mathrm{E}\right)$.

Gridded 3D wind field data from the ERA-Interim reanalysis dataset, with a temporal resolution of 6 hours, a horizontal resolution of $1^{\circ} \times 1^{\circ}$, and a vertical resolution of 26 levels from $1000 \mathrm{hPa}$ to $125 \mathrm{hPa}$ (Dee et al., 2011), were imported into the HYSPLIT model to trace the air particles responsible for the precipitation over Southeast China and to calculate specific meteorological variables along the trajectories, including altitude and specific humidity.

In the seasonal run, air particles released over Southeast China $\left(21^{\circ}-28^{\circ} \mathrm{N}, 105^{\circ}-120^{\circ} \mathrm{E}\right)$ at $1500 \mathrm{~m}$ with a horizontal resolution of $1^{\circ} \times 1^{\circ}$ during 1 April 2012 to 31 March 2013 were traced backward every 6 hours with a backward duration of 9 days, which is the approximate residence time of moisture in the atmosphere (Eagleson, 1970). The height of $1500 \mathrm{~m}$ was selected because the circulation at this level can well represent the lower-level circulation that transports most of the moisture. In the extreme precipitation run, on the other hand, the model setting was the same except the vertical resolution was set as $500 \mathrm{~m}$ from the surface to $8000 \mathrm{~m}$. Only the first 100 trajectories that contributed the most moisture during heavy rainfall events are shown.

\section{Seasonal variation of moisture sources de- tected by HYSPLIT}

To observe moisture routines systematically, the trajectories were clustered separately for the boreal summer (1 April to 30 September 2012) and winter half year (1 October 2012 to 31 March 2013) by using the Curve Clustering Toolbox (Gaffney, 2004). In selecting the number of clusters $(k)$, the in-sample log-likelihood value was calculated. This is defined as the log-probability of the observed data under the model, akin to a goodness-of-fit metric for probabilistic models (Gaffney, 2004). As is often the case, the log-likelihood values increased continuously with the number of clusters. The curves in Fig. 1 show diminishing returns in terms of improvement in fit beyond $k=6$ for the 1 April to 30 September 2012 run, and $k=4$ for the 1 October 2012 to 31 March 2013 run, suggesting that these were reasonable stopping points for the cluster analysis. Hence, for the following analysis, 6 and 4 were selected as the number of clusters for the summer and winter half-year trajectories, respectively. The variation in the altitude and specific humidity along the clustered trajectories was also examined. The specific humidity declines within Southeast China were accumulated to represent the contribution of each clustered trajectory to the moisture supply over Southeast China.

\subsection{Moisture source in the summer half year}

Six groups of moisture transport paths were identified for Southeast China during the summer half year (Fig. 2). Four key transport paths from the ocean (groups 2-5) contribute $16 \%, 31 \%, 20 \%$, and $10 \%$ of the moisture to Southeast China, respectively. The most important one (group 3) originates from the South China Sea and Bay of Bengal (SCS-BOB). It dominates the moisture transport in April and May before the onset of the Indian summer monsoon (Fig. 2c). The second most important one (group 4) originates from the central Indian Ocean and crosses the Indo-China Peninsula to Southeast China. It plays a key role in transporting moisture during May to August when the Indian summer monsoon is active (Fig. 2c). The transport path from the western Indian Ocean (group 5) contributes only half the moisture that the 

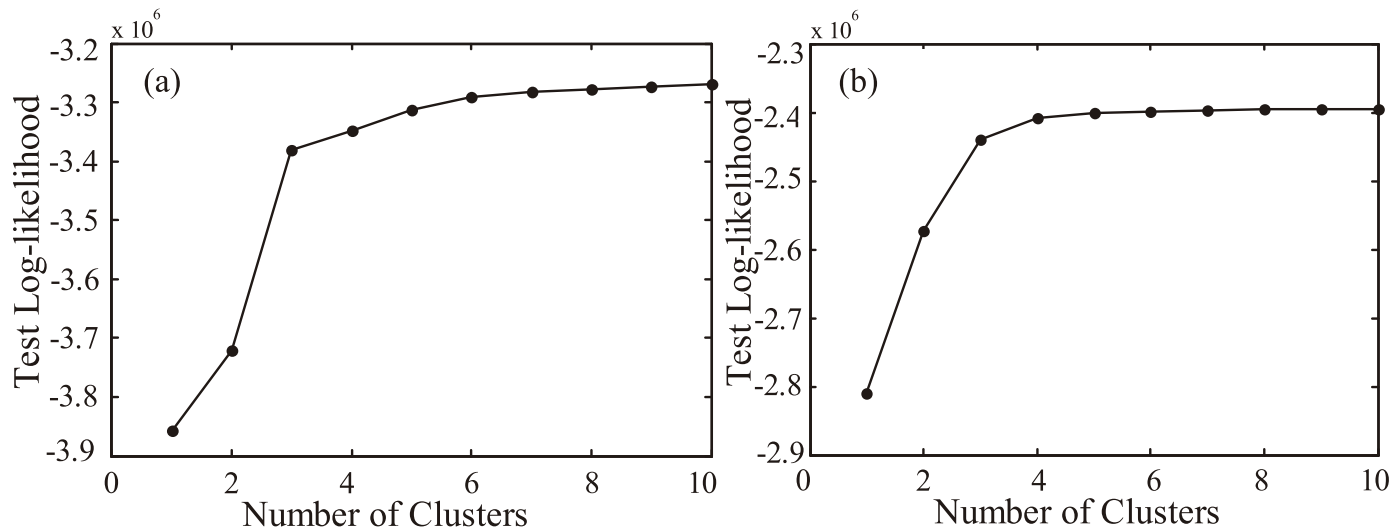

Fig. 1. Test log-likelihood values for different numbers of backward trajectory clusters: (a) 1 April to 30 September 2012 run; (b) 1 October 2012 to 31 March 2013 run.

(a) 6 groups of trajectories released over SE (APR-SEP)

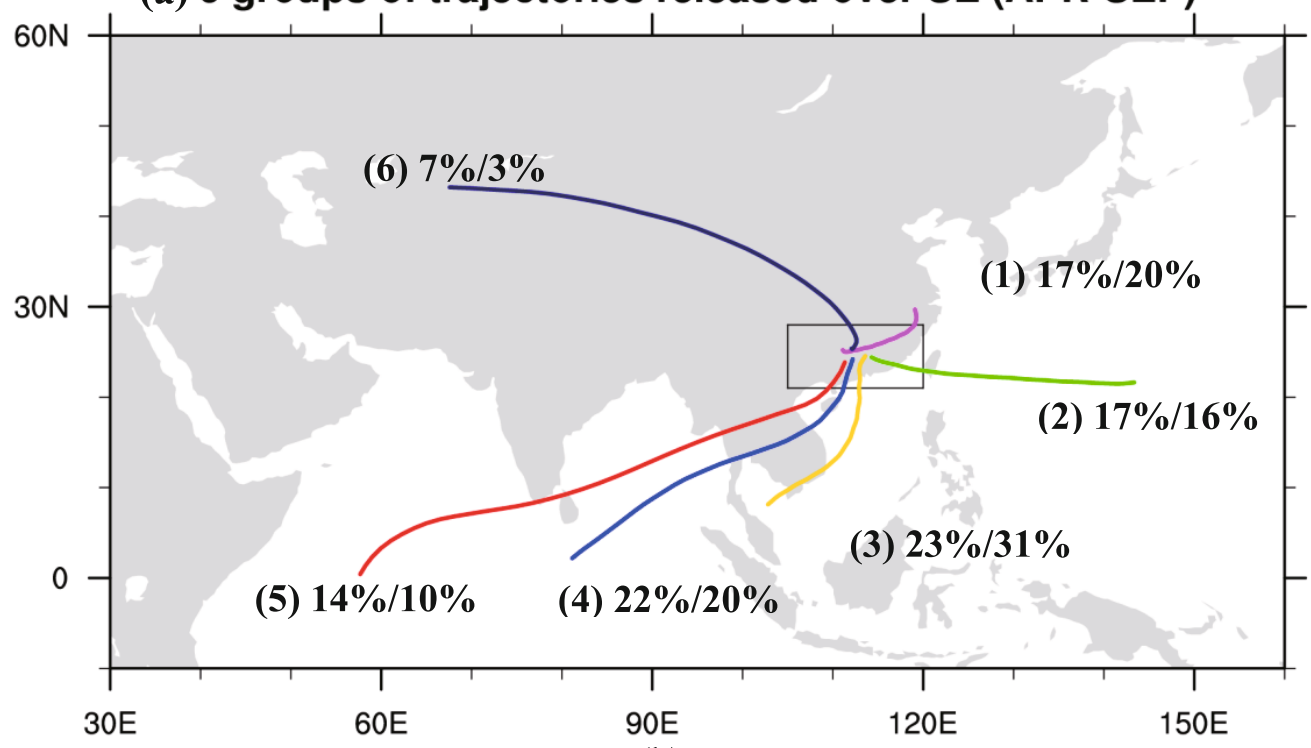

(b)

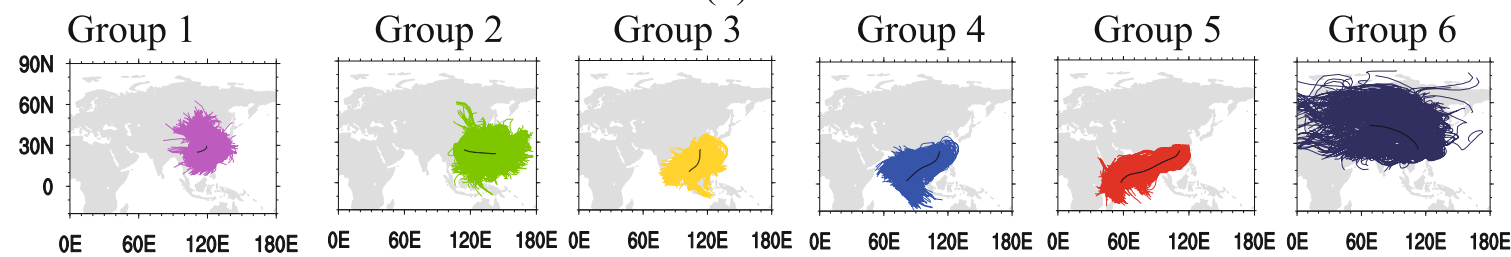

(c)

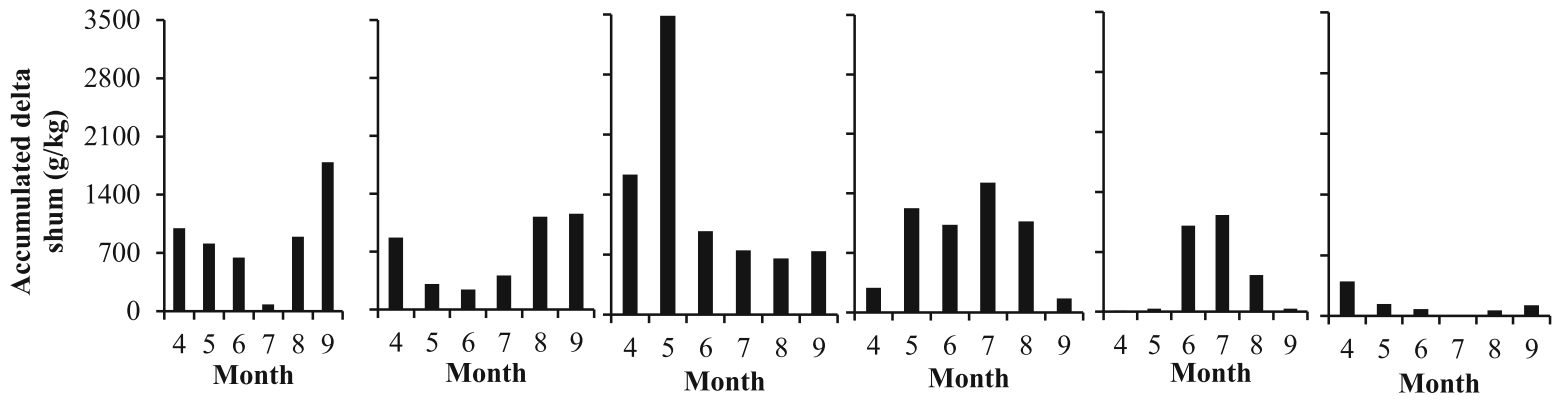

Fig. 2. Six groups of trajectories clustered based on the result of HYSPLIT during the boreal summer half year (1 April to 30 September 2012) with air particles released over Southeast China $\left(21^{\circ}-28^{\circ} \mathrm{N}, 105^{\circ}-120^{\circ} \mathrm{E}\right)$ : (a) mean trajectory of each group, with the numbers indicating the group number, percentage of trajectory amount, and the contribution to the moisture supply of each group; (b) trajectories; and (c) monthly distribution of each group. 
path from the central Indian Ocean does, and appears mainly in June and July when the Indian summer monsoon is solidly built up. Another path (group 2) from the WNP contributes around $16 \%$ of the moisture supply; it dominates in August and September when Southeast China is under the control of the western Pacific subtropical high (WPSH). The other two routines (groups 1 and 6) come from the north at higher latitudes. One is from northern China and crosses the coastal region before reaching Southeast China, with additional trajectories from the immediate neighborhood; its contribution $(20 \%)$ is equal to that from the central Indian Ocean. The other routine originates from continental Asia and reaches Southeast China from the northwest. It makes a limited contribution (3\%), as the moisture content along it is low. These two transport paths appear mainly in the early and later stages of the summer half year, which can probably be attributed to cold air activity in the reversal of seasons. Hence, based on HYSPLIT, the contributions of different moisture transport paths can be illustrated qualitatively. In spring and summer, before the establishment of the Indian summer monsoon, most of the moisture originates from the adjacent oceans, the BOB and SCS, with cold air from the north and easterly flow advected by the WPSH playing additional roles. After the onset of the Indian summer monsoon, most of the moisture originates from the Indian Ocean and is transported by the strong southwesterly flow. In the reversal period between summer and fall, the roles of the routines from the north and the WNP enhance, while the moisture advected by the Indian summer monsoon diminishes.

The composited altitude and specific humidity along each clustered trajectory were also examined (Fig. 3). Except for the routine from the inland area, the other routines from the coastal region and oceans lie at low levels with high humidity $\left(10-15 \mathrm{~g} \mathrm{~kg}^{-1}\right)$ before reaching Southeast China. They ascend with abruptly decreasing humidity during the last two days, implying that strong upward motion is associated with moisture condensation at the destination. The inland routine lies at a height of around $4000 \mathrm{~m}$, with low humidity (3 g $\mathrm{kg}^{-1}$ ) initially, and then descends and increases its moisture

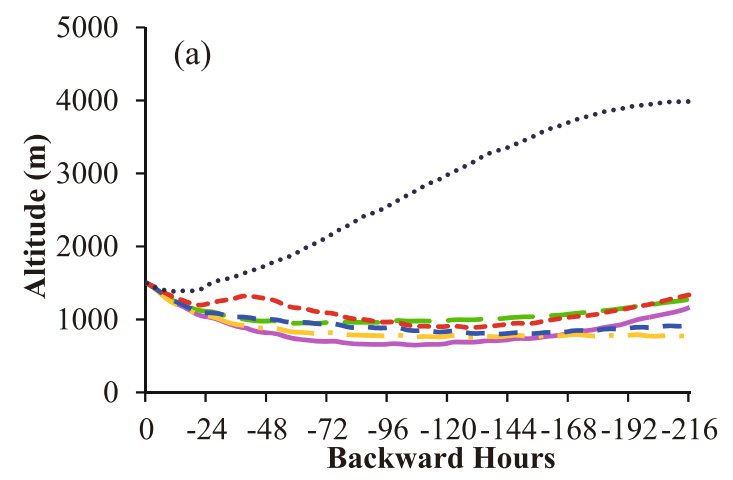

content gradually during its southward transport to the coastal region where abundant moisture can be collected. It ascends with slightly decreasing humidity in the last few hours and contributes only a small amount of moisture to Southeast China.

\subsection{Moisture source in the winter half year}

Four groups of transport routines to Southeast China were identified in the winter half year (Fig. 4). Two are from the oceans, the WNP (group 2) and BOB (group 3); one is from the north, via the coastal region, before reaching Southeast China (group 1); and the last is also from the northwest but comes mainly via the inland area (group 4). In contrast to that in the summer half year, the proportion of moisture from the WNP $(33 \%)$ is much larger than that from the Indian Ocean $(15 \%)$, indicating that more moisture originates from the WNP than from the Indian Ocean. The moisture from the WNP dominates the moisture supply in late winter and early spring. Instead of arriving in Southeast China directly from the east in the summer half year, it rotates clockwise to the SCS, and then turns northward to Southeast China, which is closely related to the southward shift of the WPSH in the winter half year. The northern BOB contributes $22 \%$ of the trajectories but only $15 \%$ of the moisture, implying that abundant moisture from the northern BOB is transported across Southeast China without condensation, as the convergencetriggering mechanism might be absent in the winter half year. This is validated in Fig. 5, as both upward motion and specific humidity decline are weak. The path from North China also appears in the winter half year, with its trajectory amount and contribution nearly double (37\%). It plays a key role in fall and early winter. Another routine, starting from southern Europe and associated with cold air activity, occupies only $15 \%$ of the moisture supply. Compared to that in the summer half year, despite the moisture content along this path being lower in the winter half year, its contribution increases dramatically, as the moisture tends to condense in the last few hours in the winter half year but not in the summer half year (Fig. 5b).

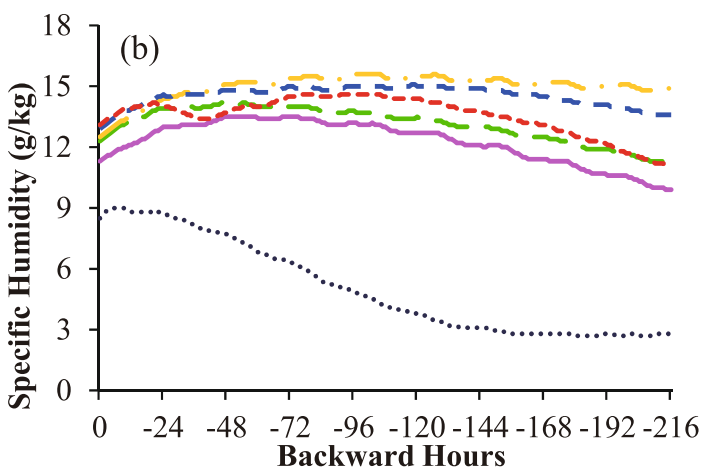

$-3---4---.5$ - $4 \cdots \cdots \cdot 6$

Fig. 3. (a) Mean altitude and (b) specific humidity along the six clustered trajectories from 9 days prior ( $-216 \mathrm{~h})$ to the moment the air particles reach the destination $(0 \mathrm{~h})$ during the boreal summer half year (1 April to 30 September 2012). 
(a) 4 groups of trajectories released over SE (OCT-MAR)

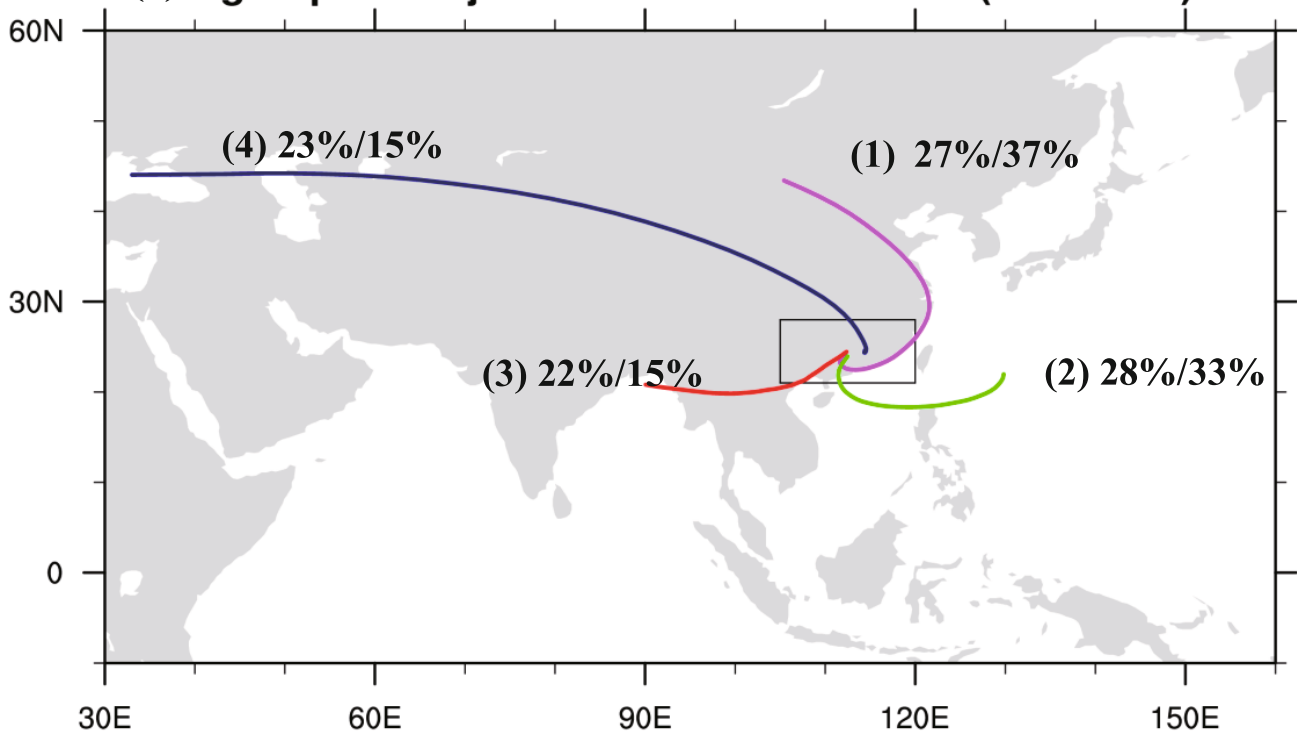

(b)
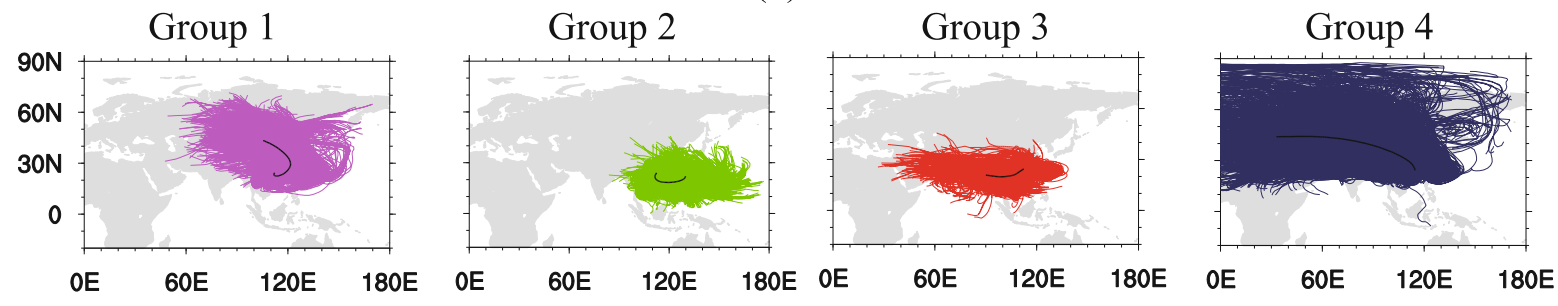

(c)
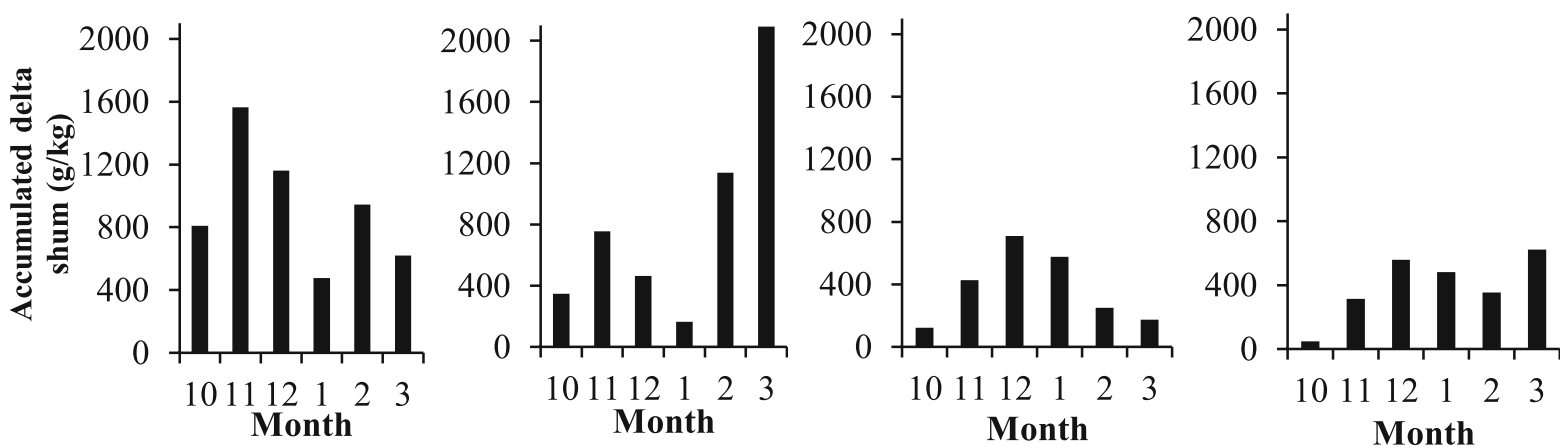

Fig. 4. As in Fig. 2 but for the four groups during the boreal winter half year (1 October 2012 to 31 March 2013).
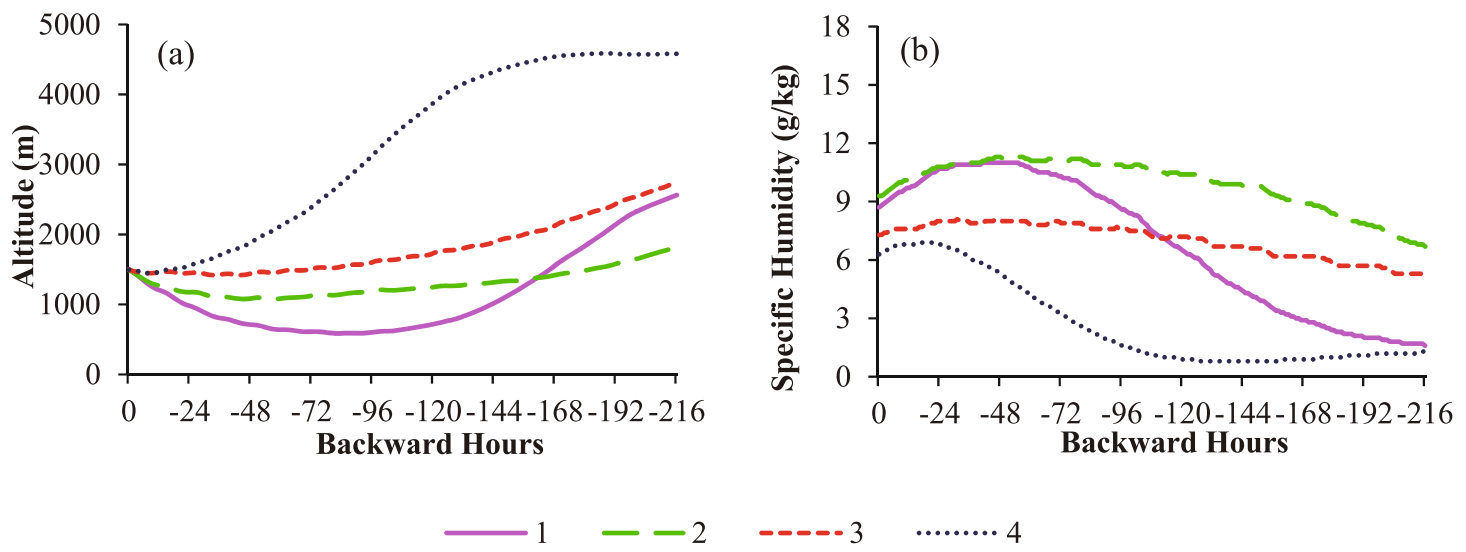

Fig. 5. As in Fig. 3 but for the four groups during the boreal winter half year (1 October 2012 to 31 March 2013). 
The composited altitude and specific humidity along the trajectories in the winter half year (Fig. 5) show that the path from the WNP is located at a low level (around $1000 \mathrm{~m}$ ), which has the highest moisture content. The path from North China descends to an even lower level and collects abundant moisture over the coastal region before reaching Southeast China. These two routines are uplifted at the destination, with humidity decreasing as moisture condenses. The path from the northwest originates at a high level with low moisture content; the humidity increases slightly before reaching the destination but does not decrease at the destination due to the lack of ascending motion, as does the routine from the northern BOB.

\section{Moisture source of heavy rainfall events de- tected by HYSPLIT}

Twenty-one regional durative heavy rainfall events were identified (Table 1). Most take place in June (38.1\%) and July (19.0\%), when the East Asian summer monsoon prevails. Some events occur in August (14.3\%) and September $(9.5 \%)$ and are closely related to the landfall of tropical storms. Some events appear in spring (14.3\%) and late fall $(4.8 \%)$, outside the rainy season. These might be triggered by vigorous cold air activity. The atmospheric circulations

Table 1. Regional heavy rainfall processes over Southeast China during 1979-2010. Based on the dominant circulations, all processes were classified into three types: (I) tropical storms; (II) interaction of the westward WPSH and cold air activity in the summer half year; and (III) strong cold air activity in the winter half year.

\begin{tabular}{ccc}
\hline No. & Date (LST) & Type \\
\hline 1 & 6-8 Apr 1981 & III \\
2 & 15-18 Jun 1982 & II \\
3 & 31 Aug to 2 Sep 1984 & I \\
4 & 27-29 Aug 1985 & I \\
5 & 29-31 Jul 1987 & II \\
6 & 30 Jun to 2 Jul 1989 & II \\
7 & 20-22 Aug 1990 & I \\
8 & 9-11 Sep 1990 & I \\
9 & 25-28 Mar 1992 & III \\
10 & 18-20 Jun 1994 & II \\
11 & 15-17 Jun 1995 & II \\
12 & 2-4 Aug 1995 & II \\
13 & 7-9 Mar1998 & III \\
14 & 19-22 Jun 1998 & II \\
15 & 9-11 Jun 2000 & II \\
16 & 17-19 Jul 2000 & I \\
17 & 20-22 Jun 2005 & II \\
18 & 15-17 Jul 2006 & I \\
19 & 7-10 Jun 2007 & II \\
20 & 12-14 Jun 2008 & II \\
21 & 31 Oct to 2 Nov 2008 & III \\
\hline & &
\end{tabular}

at different levels and the best track data from the Joint Typhoon Warning Center advisories were examined to subjectively classify three types of heavy rainfall events based on their dominant moisture circulations: (1) tropical storms; (2) interaction of the westward WPSH and cold air activity in the summer half year; and (3) strong cold air activity in the winter half year. In the following analysis, the trajectories responsible for the moisture supply during each type of heavy rainfall event are examined in detail to reveal the similarity in moisture origins and paths for each type and the differences between the types, and to compare the seasonal variation between heavy rainfall events.

\subsection{Tropical storm landing}

Seven out of 21 heavy rainfall events were directly or indirectly coupled with the landing of tropical storms. A case during 15-17 July 2006, in which accumulated rainfall reached $500 \mathrm{~mm}$, was examined. It was caused by tropical storm Bilis, which interacted intensively with the southwest summer monsoon after its landing; abundant moisture transported by the monsoon flow and strong convergence within the storm created favorable conditions for this disastrous heavy rainfall event (Zhang and Kong, 2007; Zhou, 2008; Ye and Li, 2011).

Several prominent features appear in the daily vertically integrated water vapor flux (Fig. 6a). First, the southwesterly moisture transport by the summer monsoon from the western Indian Ocean is strong. Secondly, Bilis is a center of moisture convergence; strong moisture convergence is triggered by the tropical storm and dominates Southeast China as Bilis is sustained for several days after landfall, which is crucial to the persistence of precipitation. Thirdly, the enhanced WPSH shifts westward, to the east of the landed Bilis (figure not shown), preventing further transport of southwesterly moisture flow and impelling the gathering of moisture and unstable energy over Southeast China.

This rainfall was dominated by the conjunction of a typical storm, the southwest summer monsoon, and the WPSH. Whether all these contributed to the moisture supply remains obscure from the analysis of water vapor flux. To address this question, the air particles released over Southeast China during 15-17 July 2006 were traced backward; the first 100 trajectories that contributed the most moisture are shown in Fig. 7a. The trajectories tend to originate over the eastern BOB-WNP. Compared to the summer half-year, in which moisture trajectories are from the western Indian Ocean when the Indian summer monsoon is strong (Fig. 2), the sources of moisture accompanying Bilis tend to be more localized. The storm plays a crucial role in gathering moisture and uplifting it to the condensation level. All moisture transport routines are rotated cyclonically when they get close to Southeast China. The average uplift height is above $7000 \mathrm{~km}$ (Fig. 7a), higher than that in the other types (Figs. 7b-c), which might be attributable to the strong upward motion accompanying the tropical cyclone. The specific humidity declines from around 18 to $4 \mathrm{~g} \mathrm{~kg}^{-1}$, indicating that most of the moisture is condensed into precipitation. 
(a) 15-17 July 2006

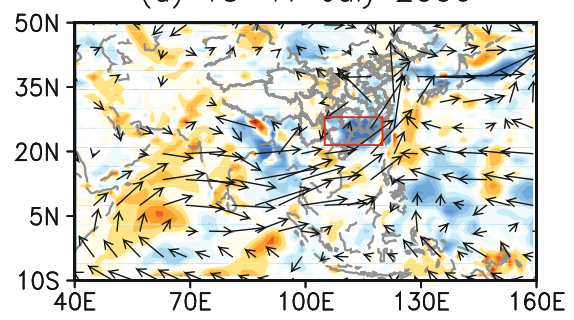

(b) 20-22 June 2005

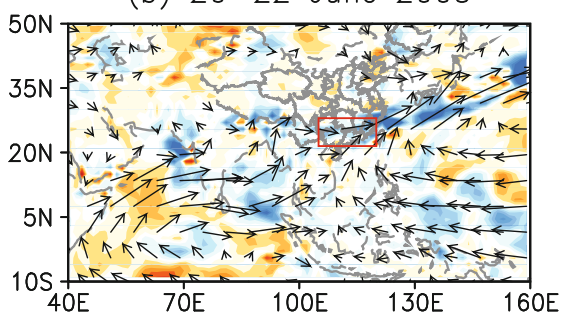

(c) 07-09 March 1998

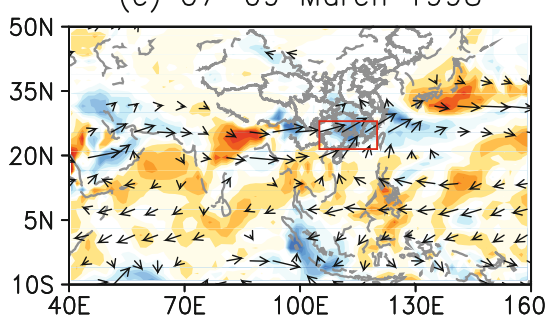

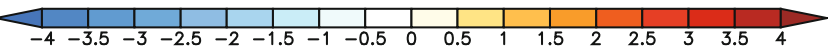

Fig. 6. Averaged vertically integrated water vapor flux (vectors; units: $\mathrm{kg} \mathrm{m}^{-1} \mathrm{~s}^{-1}$ ) and its divergence (color scale; $10^{-4} \mathrm{~kg} \mathrm{~m}^{-2} \mathrm{~s}^{-1}$ ) during (a) 15-17 July 2006, (b) 20-22 June 2005, and (c) 7-9 March 1998.

(a) 15-17 July 2006
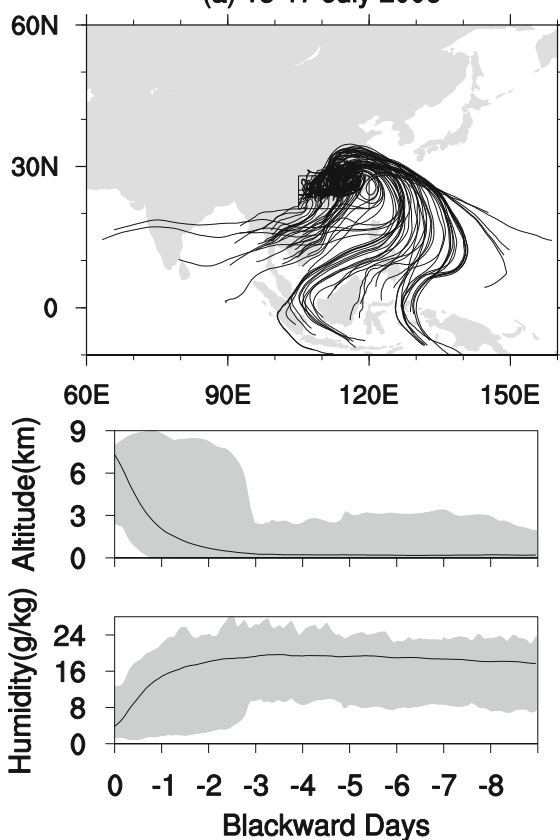

(b) 20-22 June 2005
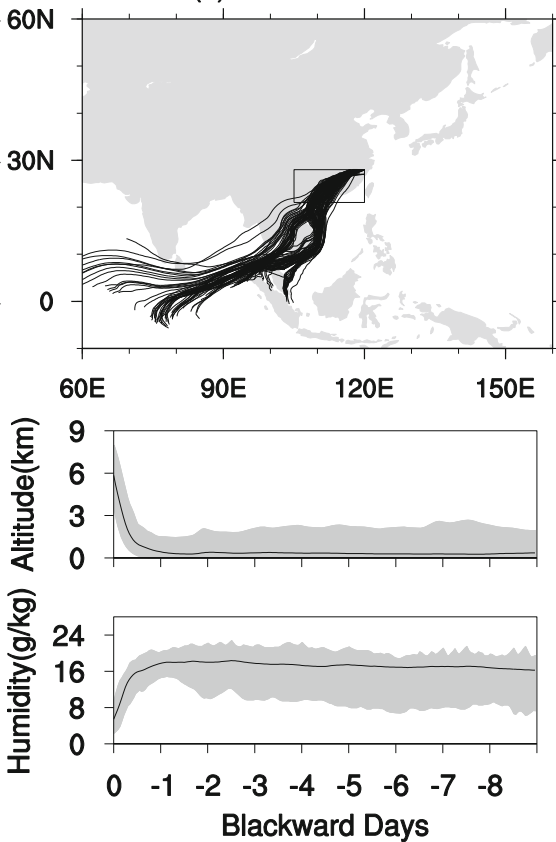

(c) 07-09 March 1998
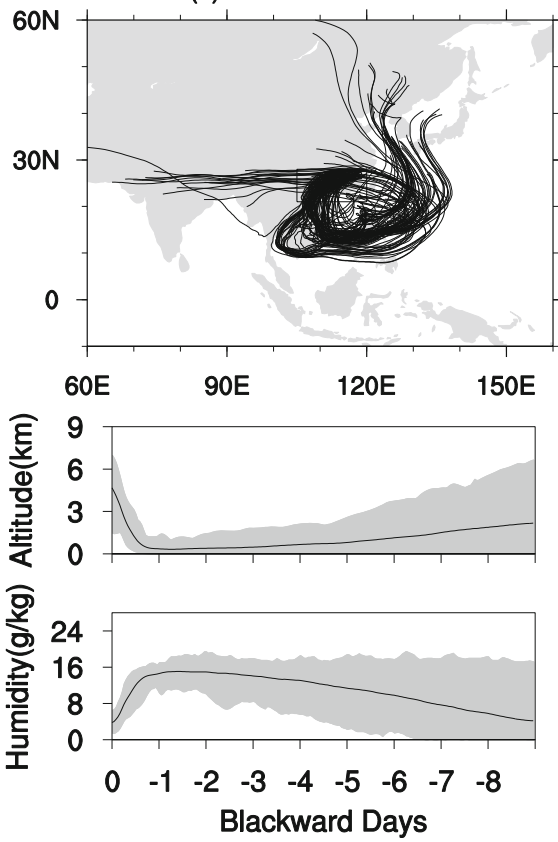

Fig. 7. The first 100 trajectories that lost the most humidity during the last 24 hours before reaching Southeast China in regional heavy rainfall cases: (a) 15-17 July 2006, (b) 20-22 June 2005, and (c) 7-9 March 1998. The upper panels show the first 100 trajectories, and the middle and lower panels show the variation in altitude and specific humidity along the trajectories, respectively, with the black lines showing the value averaged among the 100 trajectories.

The backward trajectories for the other tropical cycloneinduced heavy rainfall events are also shown in Fig. 8. Several features can be identified. First, all trajectories are rotated cyclonically when they get close to the tropical cyclone. Second, the WNP acts as an important source in the tropical storm-induced heavy rainfall events, which is reasonable, as all tropical storms affecting Southeast China originate in the WNP or SCS. This is also quite consistent with previous results in which most of the trajectories from the WNP appear in late summer, as in addition to the advection of the WPSH, tropical storms also play a role. Thirdly, the average uplift height of the air particles induced by tropical storms is high (around $7000 \mathrm{~m}$ ), except for the case during 17-19 July 2000, which was induced by a weak and short-lived storm over the SCS.

\subsection{Interaction of the westward WPSH and cold air activ- ity in the summer half year}

In the summer half year, cold air activity weakens and retreats to the north; however, when it is strong enough, it can invade southward and interact with low-latitude systems. Prefrontal warm-sector heavy rainfall is among the most common events during the first rainy season in Southeast China (Tao et al., 1980). During 17-24 June 2005, a record-breaking heavy rainfall event hit Southeast China, with daily rainfall amounts on three consecutive days in 
(a) 31 August-02 September 1984

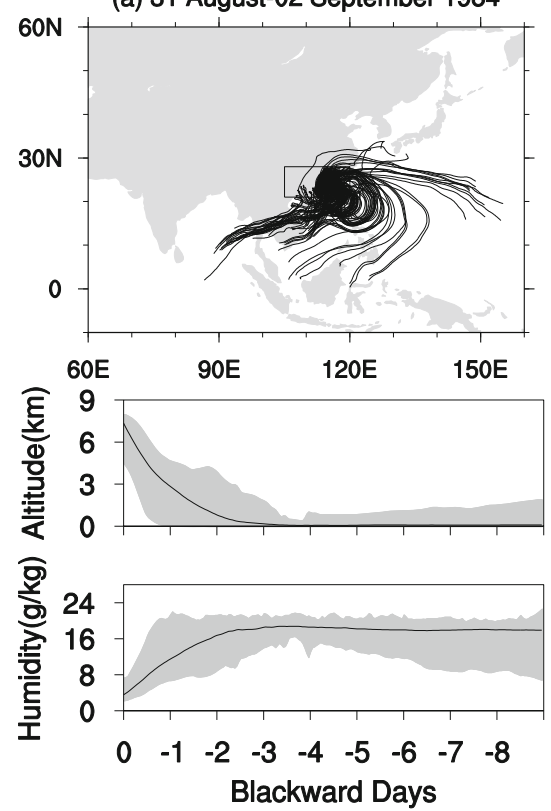

(d) 09-11 September 1990

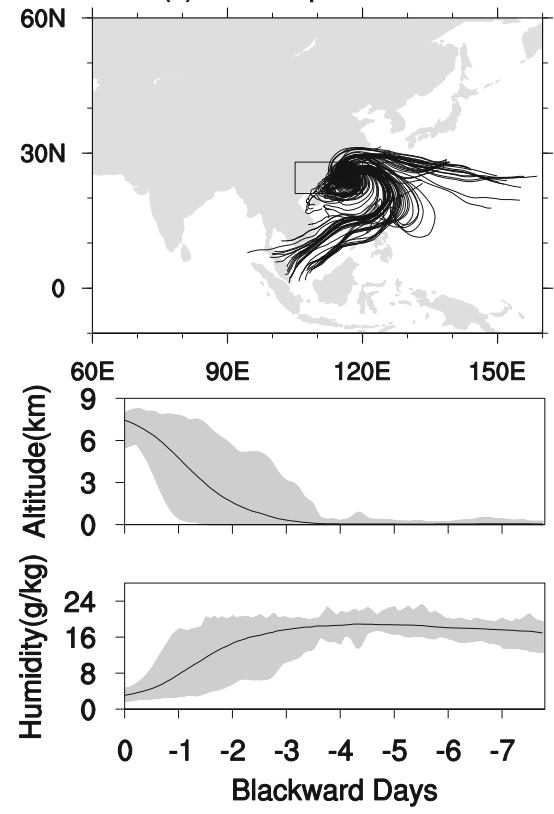

(b) 27-29 August 1985
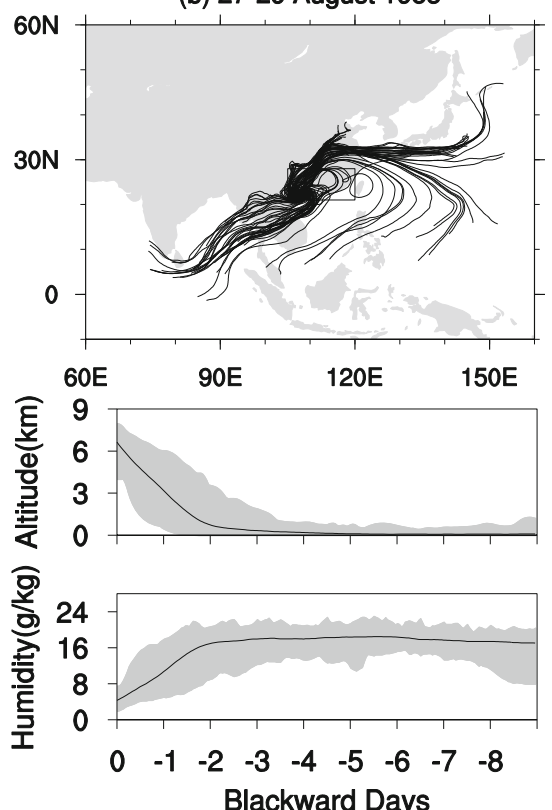

(e) 17-19 July 2000
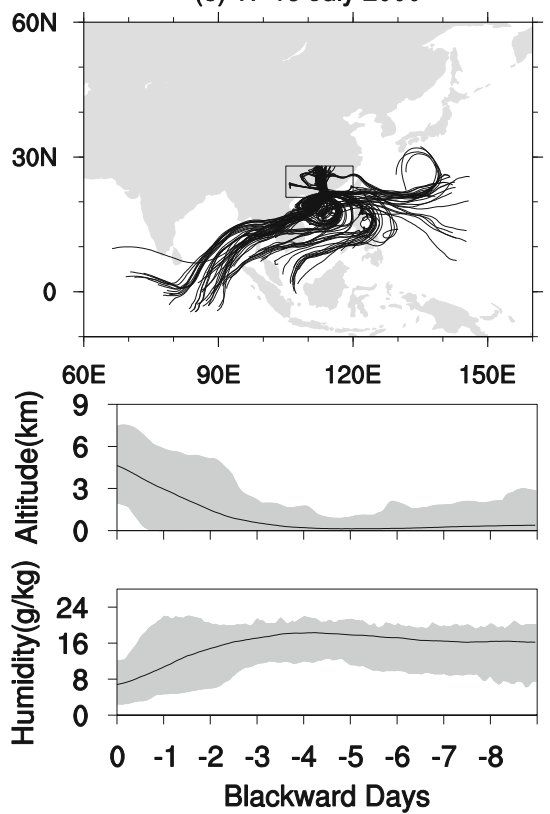

(c) 20-22 August 1990

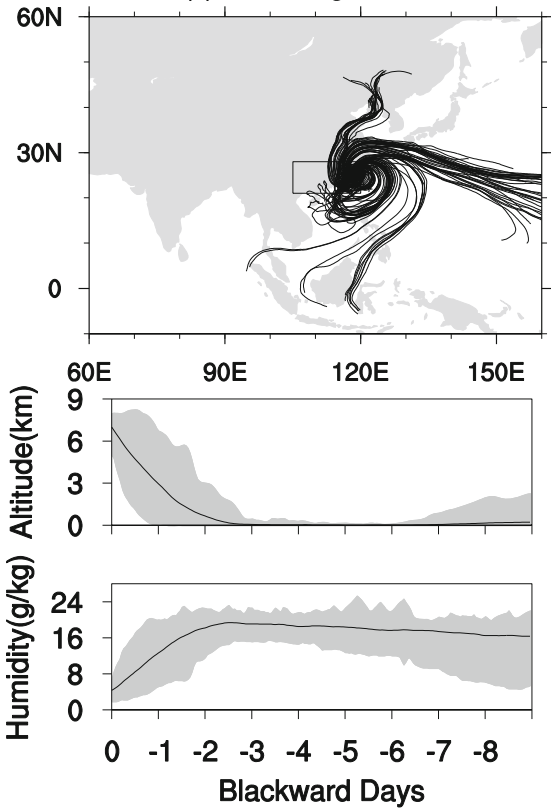

Fig. 8. The first 100 trajectories that lost the most humidity during the last 24 hours before reaching Southeast China in regional heavy rainfall cases of landfalling type I tropical storms, except during 15-17 July 2006: (a) 31 August to 2 September 1984; (b) 27-29 August 1985; (c) 20-22 August 1990; (d) 9-11 September 1990; and (e) 17-19 July 2000. The upper panels show the first 100 trajectories, and the middle and lower panels show the variation in altitude and specific humidity along the trajectories, respectively, with the black lines showing the average among the 100 trajectories.

Longmen County of 312.3, 355.0, and $310.6 \mathrm{~mm}$ (Xia and Zhao, 2009). It was a result of the combined effects of the midlevel East Asian trough, the lower-level shear line and quasi-stationary front, with the heavy rainfall occurring in the warm sector (Xia and Zhao, 2009). The WPSH enhanced and shifted southwestward and dominated the northern SCS. The conflict between the cold air guided by the midlevel trough and the humid air carried by the southwesterly flow resulted in this heavy rainfall event.
The invasion of cold air acted as a trigger for heavy rainfall; however, without sufficient moisture supply, only light or even no rainfall could be stimulated. In this case, abundant moisture diverged over the western Indian Ocean was carried by the energetic Indian summer monsoon to Southeast China, where it conflicted with the steering circulation of the southwestward-shifted WPSH (Fig. 6b). A strong Indian summer monsoon is crucial to moisture transport from the Indian Ocean to Southeast China, while the WPSH not only 

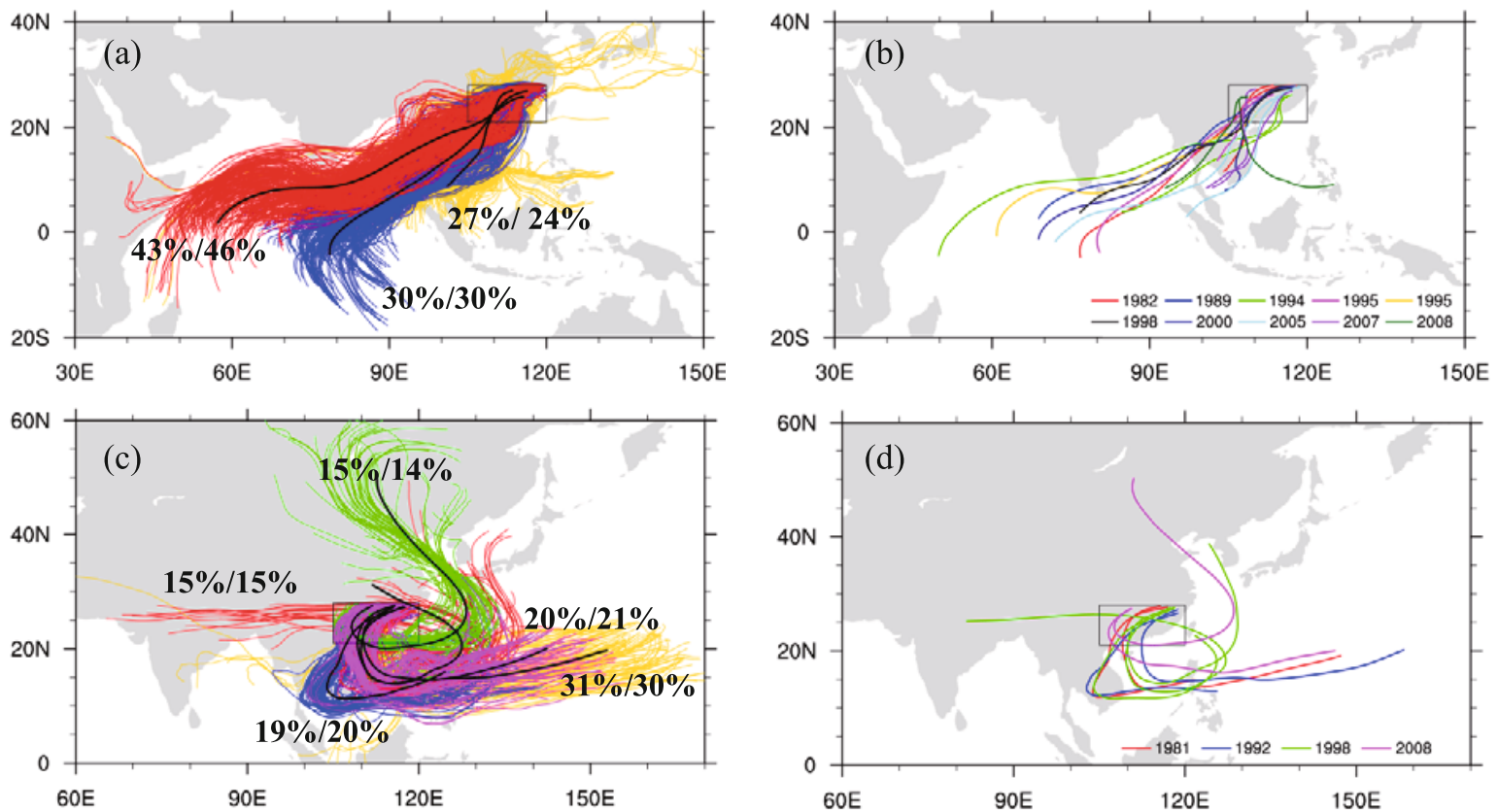

Fig. 9. Cluster analysis of (a, b) type II interaction of the westward WPSH and cold air activity in the summer half year and (c, d) type III strong cold air activity in the winter half year. In (a, c) trajectories with different colors represent different clusters, and the black line represents the composited trajectory of each cluster; in (c, d) trajectories with different colors represent clustering results in each heavy rainfall case.

acts as a dynamic barrier blocking the downstream movement of the East Asia trough and thus the persistent cold air invasion (figure not shown), but also redirects the southwesterly moisture transport to Southeast China.

The output of HYSPLIT (Fig. 7b) provides even more accurate information on the origins and paths of the moisture. Besides the western Indian Ocean, the central Indian Ocean is an important moisture source, as cross-equatorial flow is strong over that area several days before (figure not shown). According to previous results, these are two crucial moisture origins responsible for the moisture supply to Southeast China in summer when the Indian summer monsoon is active. The moisture from the WNP does not play a role in this process, implying that the WPSH helps only to redirect moisture transport but not to supply moisture from the WNP.

The composition of the moisture transport paths was also studied, based on the clustering result of trajectories for all regional heavy rainfall events (Fig. 9a) and each regional heavy rainfall event (Fig. 9b) of this type. It is shown that the western Indian Ocean, central Indian Ocean, and SCS are three key moisture sources; they were also crucial in the seasonal study. However, it is interesting to note that, in contrast to the seasonal characteristics, the importance of the western Indian Ocean is nearly twice that of the SCS. This implies that the cooperation of a strong Indian summer monsoon is essential to the heavy rainfall induced by the westward WPSH and cold air activity in the summer half year, as it transports a great deal of moisture to the rainfall region. In addition, though cold air activity plays a crucial role in triggering heavy rainfall (Xia and Zhao, 2009), it does not play a key role in supplying moisture in all regional heavy rainfall events of this type, which seems to conflict with the previous conclusion that $20 \%$ of the moisture in the summer half year is from the north and the immediate neighborhood. This might be because only the first 100 trajectories that lost the most humidity, rather than all trajectories, are shown in the analysis of regional heavy rainfall events (Fig. 9), in comparison with the seasonal analysis (Fig. 2). The routine from the north and immediate neighborhood might make a weak contribution, if any, in transporting moisture during the heavy rainfall events in the summer half year, which might be one distinguishing feature of the moisture sources between heavy rainfall events and the seasonal analysis.

\subsection{Cold air activity in the winter half year}

In spring/fall, when the northerly flow is relatively weak, humid and warm air may affect South China. When there is a sudden outbreak of strong cold air activity, the conflict between the southward-invading cold air and the preexisting warm air may trigger heavy rainfall. It was found that all heavy rainfall events outside summer (6-8 April 1981, 25-28 March 1992, 7-9 March 1998, and 31 October to 2 November 2008) occurred in a similar atmospheric pattern; that is, with a westerly flow, an anticyclone advecting abundant moisture into Southeast China from the east, and northerly flow from inland bringing cold air. The heavy rainfall during 7-9 March 1998 was the strongest rainfall in early March since 1979, inducing great damage and loss.

In the analysis of water vapor flux, the moisture converged over Southeast China during this heavy rainfall was supplied by two branches. One was transported by the westerly flow at the same latitude and the other was transported by 
an anticyclonic circulation over the SCS-WNP from the tropical WNP (Fig. 6c). Cold air activity did not play a direct role in moisture transport, as the northern boundary of Southeast China was dominated by weak southerly rather than northerly transport. Instead, it played an indirect role in the formation of the anticyclone over the SCS-WNP. In the early stage, the routine of the cold air lay mainly to the east over the ocean, where it turned clockwise toward Southeast China and converged with the westerly flow (Figure not shown). The cold air may have absorbed abundant moisture over the ocean. When the heavy rainfall took place, the other new branch of cold air from the north conflicted with the warm and humid air from the south, resulting in a strong uplifting of moisture.

The backward trajectories responsible for this heavy rainfall verify the role played by cold air activity in the moisture supply (Fig. 7c). The crucial trajectories originated from Northeast China and transported clockwise over the SCS-WNP before reaching Southeast China, where abundant moisture was absorbed. This was also proposed as the most important path for moisture transport in the winter half year in the last section. The westerly flow only played an additional role in this process.

A composite analysis of the moisture transport routines in the winter half year is shown in Figs. 9c and d. For the heavy rainfall events in the winter half year, most of the moisture originates from the WNP. Three paths from the WNP together contribute $71 \%$ of the moisture. They differ slightly in origins and paths, which might be determined by the location of the anticyclone over the WNP. The paths from the north and west contribute only $15 \%$ and $14 \%$ of the moisture, respectively. Despite other studies having suggested that westerly transport or moisture transport from the BOB are important sources of moisture in Southeast China, the present results using HYSPLIT show that the WNP is the key origin of moisture.

\section{Conclusion and discussion}

The origins and paths of moisture supplied to Southeast China were investigated using the HYSPLIT model with trajectories of air particles released over Southeast China during 1 April 2012 to 31 March 2013 and three typical regional durative heavy rainfall events. Compared to water vapor flux, the results from HYSPLIT are much more quantitative and objective. In the boreal summer half year, four key transport paths from the oceans-the WNP, SCS-BOB, central Indian Ocean, and western Indian Ocean-contribute 16\%, 31\%, $20 \%$, and $10 \%$ of the moisture to Southeast China, respectively. They experience strong upward motion and condensation within Southeast China. Coupled with the evolution of monsoon activity, the importance of each path shows great intraseasonal variation. In contrast to the summer half year, more moisture originates from the WNP $(33 \%)$ than from the Indian Ocean $(15 \%)$ in the winter half year. The path from North China plays a key role in winter moisture supply, with its trajectory amount and contribution nearly doubling (37\%) those in the summer half year.

During tropical storm-induced heavy rainfall, all moisture transport routines are rotated cyclonically by the peripheral circulation of the storm before it reaches Southeast China. The invasion of cold air can cause heavy rainfall in both the summer and winter half year, but it plays different roles in the moisture supply. In the winter half year, the routine of the cold air invasion responsible for heavy rainfall is located farther eastward than that in the summer half year. The cold air crosses the WNP, absorbs abundant moisture, and then transports it into Southeast China, thereby acting as a crucial moisture transport path. In contrast, in the summer half year, the cold air invasion over the inland area can stimulate heavy rainfall only if abundant moisture supplied by other systems is superimposed. The invasion of cold air plays a key role in converging and uplifting the moisture but not in transporting the moisture. Instead, the cooperation of a strong Indian summer monsoon is essential to the moisture supply during heavy rainfall events induced by the westward WPSH and cold air activity in the summer half year.

In this study, only the period during 1 April 2012 to 31 March 2013 was selected to analyze the seasonal variation in moisture transport, which is obviously not a long enough time span. Further analysis over longer periods would be of value. However, the period during April 2012 to March 2013 is still highly representative, as the dry/wet conditions over Southeast China during this period were normal. The percentages of the abnormal precipitation in the summer half year, winter half year, and the whole year are $2 \%, 14 \%$, and $5 \%$, respectively; all are below $0.6 \sigma$ (standard deviation). Though the HYSPLIT model is superior to water vapor flux in detecting moisture origins, caution is still advised, as it is the air particles rather than the moisture itself that are traced in the HYSPLIT model. The moisture within the air particles may experience condensation or evaporation on its path; however, the long-standing humidity content over the oceans makes it hard to tell where the moisture condenses or evaporates by analyzing the variation of the specific humidity along the trajectories. Nonetheless, the HYSPLIT model was still a useful tool for detecting the moisture transport routines in this study.

Acknowledgements. This work was financially supported by the National Nature Science Foundation of China (Project Nos. 41175079, 41405045 and 41375096) and Research Grants Council of the Hong Kong Special Administrative Region, China (Project No. CUHK441313).

\section{REFERENCES}

Bao, M., 2007: The statistical analysis of the persistent heavy rain in the last 50 years over China and their backgrounds on the large scale circulation. Chinese J. Atmos. Sci., 31, 779-792. (in Chinese)

Bao, M., and R. H. Huang, 2006: Characteristics of the interdecadal variations of heavy rain over China in last 40 years. Chinese J. Atmos. Sci., 30, 1057-1067. (in Chinese)

Brimelow, J. C., and G. W. Reuter, 2005: Transport of atmo- 
spheric moisture during three extreme rainfall events over the Mackenzie River Basin. J. Hydrometeor, 6, 423-440.

Dee, D. P., and Coauthors, 2011: The ERA-Interim reanalysis: Configuration and performance of the data assimilation system. Quart. J. Roy. Meteor. Soc., 137, 553-597.

Ding, Y. H., 1994: Monsoons over China. Kluwer Academic Publisher, $419 \mathrm{pp}$.

Draxler, R. R., and G. D. Rolph, 2003: HYSPLIT-Hybrid Single Particle Lagrangian Integrated Trajectory Model. Silver Spring [Available online at http://www.arl.noaa.gov/ready/ hysplit4.html.]

Eagleson, P. S., 1970: Dynamic Hydrology. McGraw-Hill, Inc, 462 pp.

Fuhrmann, C. M., and C. E. Konrad II, 2013: A trajectory approach to analyzing the ingredients associated with heavy winter storms in central North Carolina. Wea. Forecasting, 28, 647-667.

Gaffney, S., 2004: Probabilistic curve-aligned clustering and prediction with mixture models. PhD dissertation, Department of Computer Science, University of California, Irvine, $281 \mathrm{pp}$.

Gustafsson, M., D. Rayner, and D. L. Chen, 2010: Extreme rainfall events in southern Sweden: Where does the moisture come from? Tellus A, 62, 605-616.

Jiang, Z. H., Z. R. Liang, Z. Y. Liu, and Y. L. Zhu, 2011: A diagnostic study of water vapor transport and budget during heavy precipitation over the Huaihe River basin in 2007. Chinese J. Atmos. Sci., 35, 361-372. (in Chinese)

Li, X. Z., W. Liang, and Z. P. Wen, 2010: Characteristics of the atmospheric water vapor and its relationship with rainfall in south China in northern autumn, winter and spring. Journal of Tropical Meteorology, 26, 626-632. (in Chinese)

Li, X. Z., Z. P. Wen, W. Zhou, and D. X. Wang, 2012: Atmospheric water vapor transport associated with two decadal rainfall shifts over East China. J. Meteor. Soc. Japan, 90, 587-602.

Qin, J., L. N. Pan, and L. Shi, 1991: Influences of the southern trough and strong cold air on the winter weather over Yunnan province. Meteorological Monthly, 17, 39-43. (in Chinese)

Stohl, A., and Coauthors, 2003: A backward modeling study of intercontinental pollution transport using aircraft measurements. J. Geophys. Res., 108(D12), ACH 8-1-ACH 8-18.

Tao, S. Y., and Y. H. Ding, 1981: Observational evidence of the influence of the Qinghai-Xizang (Tibet) Plateau on the occurrence of heavy rain and severe convective storms in China. Bull. Amer. Meteor. Soc., 62, 23-30.

Tao, S. Y., and Coauthors, 1980: The Torrential Rain in China. Science Press, Beijing, 225 pp. (in Chinese)

Trenberth, K. E., A. G. Dai, R. M. Rasmussen, and D. B. Parsons, 2003: The changing character of precipitation. Bull. Amer. Meteor. Soc., 84(9), 1205-1216, doi: 10.1175/BAMS-84-91205.

Xia, R. D., and S. X. Zhao, 2009: Diagnosis and modeling of meso- $\beta$-scale systems of heavy rainfall in warm sector ahead of front in South China (middle part of Guangdong province) in June 2005. Chinese J. Atmos. Sci., 33, 468-488. (in Chinese)

Ye, C. Z., and J. Y. Li, 2011: A numerical study of the characteristics of strong moisture transport as a result of the interaction of tropical storm Bilis with the South China Sea monsoon. Acta Meteorologica Sinica, 69(3), 496-507. (in Chinese)

Zhang, H. D., and Q. Kong, 2007: Diagnostic analysis of severe tropical storm Bilis heavy rain event. Meteorological Monthly, 33(5), 42-48. (in Chinese)

Zhou, H. G., 2008: 3D structure of the heavy rainfall caused by Bilis (0604) with Doppler radar data. Chinese J. Atmos. Sci., 32(6), 1289-1308. (in Chinese) 